\section{AB0083 LOCAL ICE CRYOTHERAPY DECREASES PROSTAGLANDIN-E2, NF-KB AND IL-6 SYNOVIAL LEVELS IN ARTHRITIC KNEES COMPARED TO CONTRALATERAL NON-TREATED JOINTS}

X. Guillot ${ }^{1,2,3}$, N. Tordi ${ }^{2}$, C. Laheurte ${ }^{4}$, L. Pazart ${ }^{5}$, C. Pratit ${ }^{2,3}$, P. Saas ${ }^{4}$, D. Wendling ${ }^{3,6} .{ }^{1}$ Rheumatology Department, Felix Guyon University Hospital, Saint-Denis, Réunion; ${ }^{2}$ PEPITE EA4267, FHU Increase, Bourgogne-FrancheComté University; ${ }^{3}$ Rheumatology Department, ${ }^{4}$ INSERM U1098, Biomonitoring Platform, EFS; ${ }^{5}$ CIC IT, INSERM Center CIT 808, Besançon University Hospital; ${ }^{6}$ EA 4266, Bourgogne-Franche-Comté university, Besançon, France

Background: Cryotherapy is widely used in rheumatic diseases, with a low level of evidence. Tissue mild hypothermia was reported to inhibit pivotal pro-inflammatory enzyme pathways such as COX-2/PG-E2 ${ }^{1}$ and NF-kB. ${ }^{2}$

Objectives: We hypothesised that local cryotherapy (LC) might reduce joint inflammation through PG-E2 and NF-kB repression.

Methods: 47 patients suffering from non-septic knee arthritis were included (17 gouts, 11 calcium pyrophosphate dehydrate crystal deposition diseases, 6 spondyloarthritides, 13 rheumatoid arthritides), taking no concurrent anti-inflammatory drug/DMARD. They were first randomised to receive local ice (30 min- $\mathrm{N}=16$ ) or cold pulsed $\mathrm{CO} 2$ (2 min - Cryo+ Cryonic-N=16) at 9 A.M and 5 P.M. Synovial fluid was collected just before the first cold application then 24 hours later (9 A.M). Synovial fluid IL-6, IL-1 $\beta$, TNF- $\alpha$, IL-17A, VEGF (Multiplex flow cytometry), NF-kB P65 (total/phosphorylated) and PG-E2 (ELISA) were measured and compared before and after 2 LC applications. Contralateral non-treated knees were then used as paired controls (in 16 other ice-treated patients).

Results: Synovial IL- 6 significantly decreased after 2 LC applications ( $n=43$ paired Wilcoxon: $p=0.00015)$. This decrease was also significant in ice-treated subgroup $(n=16 p<0.005)$ but not in CO2-treated patients $(n=14 ; p=0.1)$. IL-1 $\beta$ and VEGF levels also decreased after treatment $(n=44-p=0.02$ and $n=47-p=0.03)$ but not significantly in treatment subgroups. By contrast, IL-6 $(n=13), I L-1 \beta \quad(n=15)$ and VEGF $(n=15)$ didn't change in contralateral non-treated knees. LC had no significant effect on IL-17A nor TNF- $\alpha$ synovial levels. LC significantly reduced synovial NF-kB $(n=38-p=0.04)$ and NF-kB-P levels $(n=38-p=0.004)$. These levels were also significantly decreased in ice-treated patients $(n=26-p=0.03$ and 0.003$)$ but not in CO2-treated patients $(n=13)$. We observed no effect on the NF-kB levels in contralateral non-treated knees $(n=12)$. NF-kB variations correlated significantly with IL-6 (Pearson's $r=0.48-\mathrm{N}=32 \mathrm{p}<0.01)$ and VEGF $(r=0.34-\mathrm{N}=36-\mathrm{p}=0.038)$ variations, and with the maximal skin temperature drop induced by $\mathrm{LC}(\mathrm{r}=0.32-\mathrm{N}=36-$ $\mathrm{p}=0.047)$. LC significantly reduced synovial PG-E2 $(n=38-\mathrm{p}=0.04)$, which was also significantly decreased in ice-treated patients $(n=26-p=0.02)$ but not in $\mathrm{CO}$ treated patients $(n=13)$. Conversely, we observed a significant increase in PG-E2 levels in contralateral non-treated knees $(n=12-p=0.04)$, with a significant interclass effect-size (weighted mean difference -1329 [-2232;-426] pg/mL-in 12 biarthritic patients).

Conclusions: Local ice cryotherapy applied twice during one day showed superior anti-inflammatory effects compared to local $\mathrm{CO} 2$, notably by reducing synovial IL-6 levels in arthritic knees. We also showed for the first time that this inhibitory effect on cytokine levels might be PG-E2 and NF-kB dependent, notably through significant inhibitory effects on the PG-E2 and (to a lesser extent) NF-kB pathways.

\section{REFERENCES:}

[1] Diestel. Cryobiology 2008.

[2] Yenari. Neurochem Int 2006.

Disclosure of Interest: None declared

DOI: 10.1136/annrheumdis-2018-eular.5056

\section{$\mathrm{AB} 0084$ \\ ELEVATED LEVELS OF IL-37 ARE ASSOCIATED WITH TOPHUS AND SUPPRESSED THE PRODUCTION OF INFLAMMATORY CYTOKINES IN PATIENTS WITH GOUT}

X. Hong, L. Ding, Q. Huang, D. Liu. Department of Rheumatology and Immunology, Shenzhen People's Hospital, the Second Clinical Medical College of Jinan University, Shenzhen, China

Background: IL-37 has been identified as a natural inhibitor of innate immunity Although increasing evidence shows elevated IL-37 expression in various autoimmune diseases, its correlation with clinical symptoms in gout is still unclear.

Objectives: This study aims to determine the correlation between the levels of IL37 and clinical indexes in gout patients, and to examine the inhibitory effect of IL37 on pro-inflammatory cytokine including IL-1 $\beta$, IL- 6 and IL-18 from peripheral blood mononuclear cells (PBMC) of gout patients in culture.

Methods: Levels of serum IL-37 and concentrations of IL-1 $1 \beta$, IL-6, IL-18 in cell culture from 42 patients with gout and 40 healthy controls ( $\mathrm{HCs}$ ) were measured by enzyme-linked immunoassay (ELISA). Moreover, the relative mRNA

expression of these cytokines in PBMCs was detected by real-time PCR (RTPCR). The correlations between serum IL-37 levels and clinical values in gout patients were analysed by Spearman correlation test.

Results: Both protein and mRNA levels of IL-37 were higher in gout patients than healthy controls, especially in patients with tophus. Serum IL-37 levels of gout patients were positively correlated with $\mathrm{C}$-reactive protein and uric acid. Furthermore, the expression of IL-1 $\beta$, IL- 6 and IL-18 in PBMCs from gout patients was significantly increased, which were markedly suppressed by IL-37 in culture.

A
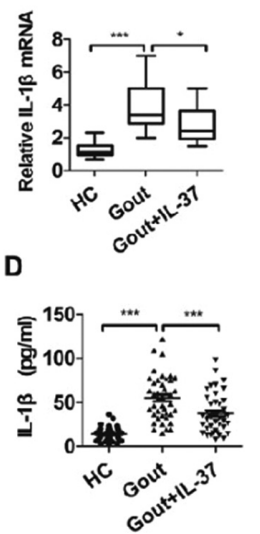

E
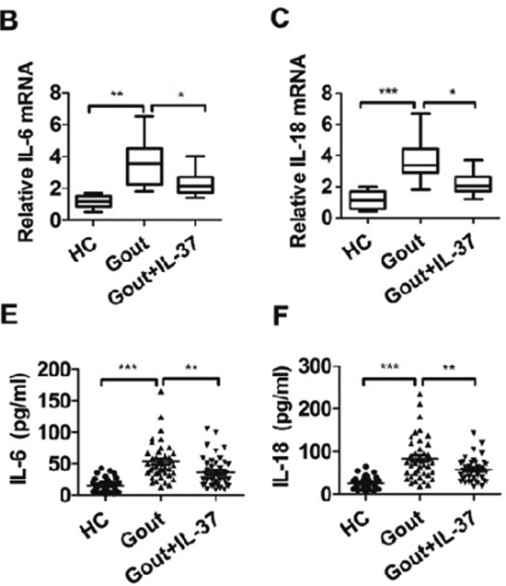

Abstract AB0084 - Figure 1. IL-37 suppresses the expression of pro-inflammatory cytokines in PBMCs from gout patients

Conclusions: Serum levels of IL-37 are closely associated with clinical symptoms in gout patients and may represent a potential biomarker for the disease activity

\section{REFERENCES:}

[1] Richette P, Bardin T. Gout. Lancet 2010;375(9711)318-28.

[2] Masters SL, Simon A, Aksentijevich I, Kastner DL. Horror autoinflammaticus: the molecular pathophysiology of autoinflammatory disease. Annu Rev Immunol 2009;27(2009)621-68.

[3] Martinon F, Petrilli V, Mayor A, Tardivel A, Tschopp J. Gout-associated uric acid crystals activate the NALP3 inflammasome. Nature 2006;440 (7081)237-41.

[4] Emmerson BT. The management of gout. N Engl J Med, 1996;334(7)44551.

[5] Fiechtner JJ, Simkin PA. Urate spherulites in gouty synovia. JAMA $1981 ; 245(15) 1533-6$.

Disclosure of Interest: None declared DOI: 10.1136/annrheumdis-2018-eular.2269

\section{AB0085 \\ THE MECHANISM OF TOTAL GLUCOSIDE OF PAEONY AND SINOMENINE ON THE PREVENTION OF ACUTE GOUT FLARES}

Z. Li, X. Ma, D. Li, Z. Lu. Rheumatology, Bethune International Peace Hospital, Shijiazhuang, China

Background: The compliance of drug prevention for acute gout flares (GFs) during urate-lowering treatment (ULT) is very low. New preventive drugs of GFs during ULT is required. Our previous study found that the total glucoside of paeony (TGP), a traditional Chinese drug's extracts, has a good effect on the prevention and treatment for urate induced acute gouty arthritis (AGA) in rat.

Objectives: To explore the possible mechanism of TGP and Sinomenine (SIN) in the prevention and treatment of acute gouty arthritis.

Methods: Logarithmic growth phase of RAW264.7 cells were seeded into 96 well plate at a density of $5 \times 10^{4} / \mathrm{mLI}$. Cultured overnight in a humidified atmosphere of $5 \% \mathrm{CO}_{2}$ at $37^{\circ} \mathrm{C}$. Then, the medium was changed to serum-free DMEM. Then divided into Control group (DMEM), Model group (DMEM $+50 \mathrm{mg} / \mathrm{L} \mathrm{MSU}$ ), Colchicine group (DMEM $+50 \mathrm{mg} / \mathrm{L} \mathrm{MSU}+1$ umol/L Colchicine), TGP group (DMEM $+50 \mathrm{mg} / \mathrm{L} \mathrm{MSU}+40 \mathrm{mg} / \mathrm{L}$ TGP), SIN group (DMEM $+300 \mathrm{mmol} / \mathrm{L} \mathrm{SIN}$ ), SIN +TGP group (DMEM +40 mg/L TGP +300 mmol/L SIN). The final volume of solution was $2 \mathrm{ml}$ in each well, and each group had 3 wells, culturing for 24 hour in a humidified atmosphere of $5 \% \mathrm{CO}_{2}$ at $37^{\circ} \mathrm{C}$. Then, culture supernatant was collected. NO level were detected by method of nitrate reductase, the level of IL-1 $1 \beta$, 